\title{
The impact of the availability of antiretroviral therapy on personal and community fear of HIV/AIDS, and HIV prevention practices in Rwimi, Uganda: A mixed-method study
}

Nicole N. Ofosu' ${ }^{1}$, L. Duncan Saunders', Gian Jhangri' ${ }^{1}$, and Arif Alibhai ${ }^{1}$.

'Population Health Intervention Research Unit, School of Public Health, University of Alberta, 3-50 University Terrace, 8303 - 112 Street, Edmonton, Alberta, Canada T6G 2T4.

\section{Key points:}

- The impact of the widespread availability of highly active anti-retroviral (ART) therapy on HIV/AIDS prevention practices in Sub-Saharan Africa is understudied.

-In Rwimi, Uganda, the fear of human immunodeficiency virus and acquired immune deficiency syndrome (HIV/ AIDS) persists; however, with the availability of life-prolonging ART, this fear is reduced.

-HIV/AIDS prevention practices in Rwimi are influenced by socio-cultural norms such as gender roles, relationship dynamics and trust which should be considered when designing HIV prevention programs.

\begin{abstract}
The impact of the widespread availability of antiretroviral therapy (ART) on the human immunodeficiency virus and acquired immune deficiency syndrome (HIV/AIDS) related attitudes, behaviours and practices of the general population in Sub-Saharan Africa is understudied. We assessed the impact of ART availability on the fear of HIV/ AIDS (measured at both community and personal levels) and HIV prevention practices in Rwimi, Uganda using a cross-sectional survey. The fear of HIV/AIDS was described as a perceived threat to either self and/or community regarding the risk of contracting the disease, whereby the higher the perception of the threat, the greater the fear. We assessed associations between the outcomes of the dependent variables on both the community and personal fear of HIV/AIDS, and the independent variables of HIV/AIDS-related knowledge and demographics. Qualitative data was also generated from focus group discussions (FGD) on the context of the fear of HIV/AIDS and HIV pre- vention practices. The majority of participants $(89.4 \%$; males $-86.8 \%$; females $-90.8 \%)$ felt that ART availability has reduced the fear of HIV/AIDS in the community. In contrast, fewer participants (22.4\%; males $-24.4 \%$; females $-21.2 \%$ ) mentioned that their personal fear of HIV/AIDS has been reduced with the availability of ART. From the qualitative study, factors identified as influencing the fear of HIV/AIDS included stigma, fear of infection, and the inconvenience of being on ART. Although fear of HIV/AIDS persists, the fear is reduced because of the availability of life-prolonging ART. HIV prevention practices are influenced by socio-cultural norms (gender roles, relationship dynamics, power and trust), which, we argue, should be considered when designing sustainable HIV/AIDS prevention programs.
\end{abstract}

Key words: Africa, anti-retroviral therapy, attitudes, knowledge, prevention

Corresponding author, Nicole N. Ofosu, lartey@ualberta.ca. 


\section{Introduction}

Antiretroviral therapy (ART) comprises a combination of drugs used to treat the human immunodeficiency virus (HIV) by suppressing the progression of the disease (World Health Organization 2017). Consequently, access to and proper use of ART results in a dramatic reduction in the incidence of acquired immune deficiency syndrome (AIDS) and death in individuals infected with HIV, thereby prolonging and improving quality of life (Apondi et al. 2011; The Antiretroviral Therapy Cohort Collaboration 2005; World Health Organization 2014). There is, however, a concern about the availability of ART producing a negative effect on sexual behaviour resulting in relapse back into or continued risky behaviours among people living with HIV/AIDS and their sexual partners (Demmer 2003; Luchters et al. 2008; Moatti et al. 2003). Such undesirable changes in sexual behaviour have been attributed to "treatment optimism" - the belief that ART mitigates the risk and consequences of HIV/AIDS infection (Kaye et al. 2013; Nachega et al. 2005). Studies in developed countries have shown an increase in unprotected sex with the availability of ART, particularly among homosexual males (Diabate et al. 2008; Ostrow et al. 2002; Stolte et al. 2004). In Sub-Saharan Africa, which bears the highest number of HIV/AIDS cases, some studies have found an association between ART availability and sexually risky behaviour among persons on ART (Diabate et al. 2008; Pearson et al. 2011). However, studies regarding the impact of ART availability on the general population (including people living without HIV/AIDS) are rare, especially in Sub-Saharan Africa. There is a growing need for more comprehensive studies, which include the general population, to provide a more complete assessment of the impact of ART on sexual behaviour and HIV preventive endeavours.

Uganda is one of the countries in Sub-Saharan Africa with long-standing HIV/AIDS intervention programs. In 2004, Uganda began to scale-up access to free ART medication to people living with HIV/AIDS; by 2013, 69.4\% of eligible people living with HIV/AIDS in Uganda were receiving ART (Uganda AIDS Commission 2014). Subsequently, HIV/AIDS prevalence has increased as people living with HIV have gained access to treatment. However, risky sexual practices such as having multiple sexual partners and declining condom use are prevalent (Uganda AIDS Commission 2014; UNAIDS 2013). This echoes the concerns of a disinhibiting effect of ART on sexual behaviour and has generated an interest in the impact of ART on attitudes, behaviours and HIV prevention practices. Therefore, we assessed the impact of the widespread availability of ART on attitudes (specifically, fear of HIV/AIDS), behaviours and HIV prevention practices in Rwimi, Uganda.

\section{Methods}

\subsection{Study Population}

The Uganda National Council of Science and Technology and the Institutional Review Boards of Makerere University, Uganda and the University of Alberta, Canada approved this study. Written consent was also obtained from participants.

We conducted a mixed-method study (a crosssectional study with a qualitative description) among the general population in Rwimi, Uganda. Rwimi is a rural county in the Kabarole District of Uganda, where ART has been accessible since 2006 through a joint Ugandan government and Canadian university program. The first part of the study, a cross-sectional random cluster survey, was conducted between June to August 2013 with 639 participants enrolled from 32 villages in Rwimi. We systematically sampled 20 households in 31 villages and 19 households in 1 village. In each household, one individual aged between 18 to 49 years - who was present at the time of the survey - was randomly selected to participate. Participants were excluded if they mentioned they were on ART; however, we did not ask about the HIV/AIDS status of eligible participants due to ethical concerns. Participants were also excluded if they did not speak Rutooro or English and did not live in Rwimi.

The qualitative description study was included to enhance the description and understanding of our research findings (Morse and Niehaus 2009). Participants were purposefully sampled from the survey participants within the following four groups: a) males with a self-perceived low risk of HIV/AIDS, b) females with a self-perceived low risk of HIV/AIDS, c) males with a self-perceived high risk of HIV/AIDS and d) females with a self-perceived high risk of HIV/AIDS. There were 6 to 7 participants in each of the focus group dis- 
cussions (FGD) totaling 26 participants.

\subsection{Data Collection}

\subsubsection{Cross-Sectional Study}

Survey questions were derived from studies conducted in Uganda and Kenya on HIV/AIDS-related knowledge, attitudes and practices (Aplin 2012; Smith et al. 2011). Additional questions were included to assess whether the availability of ART has reduced the fear of contracting HIV/AIDS at the community level and personal levels. Fear of HIV/AIDS was defined as a perceived threat to self or community with regard to the risk of contracting the disease, whereby the higher the perception of the threat, the greater the fear (Muthusamy et al. 2009). The questionnaire consisted of sections on (i) participant's demographic background, (ii) knowledge on HIV/AIDS, (iii) attitudes towards HIV/ AIDS and ART and (iv) current HIV/AIDS preventive practices. Trained local research assistants administered the questionnaires in Rutooro but recorded the answers in English. After the survey, the data gathered was entered into an Epi Info 7 database and checked for completeness and accuracy.

Data from the survey was analyzed with STATA12 (StataCorp 2011). The data was weighted for the cluster sampling design. Means and frequencies were used to summarize the characteristics of the study population and to describe measures of HIV/AIDS-related knowledge, attitudes and practices. The measures, "Do you think the fear of HIV/AIDS has reduced now that ART is available?" and "Are you less fearful of HIV/ AIDS now that ART is available?" were selected as dependent variables for multivariable logistic regression models. Demographic variables and selected knowledge measurements were used as independent variables.

\subsubsection{Qualitative Description}

Data was generated through FGD conducted in the local language of Rutooro. Verbal consent for participants' involvement, including audio-recording of the interviews, was obtained. Each FGD lasted approximately 60 to 75 minutes and was moderated by a research assistant who was fluent in both English and Rutooro. A second research assistant assisted in note taking. Although a topic guide was used, participants were encouraged to speak freely in order to have a participant-driven data collection. The interviews were transcribed verbatim and translated into English by the research assistant who moderated the FGD. Inter- terviews were reviewed to ensure that saturation had been reached and there were no more leads to follow for further information. Transcription accuracy was verified and data was imported into Atlas.ti7 (ATLAS. ti7 Student Semester License).

Content analysis, which is appropriate for the qualitative description approach, was used for the analyses (Mayan 2009; Sandelowski 2000). Codes were grouped into categories which were reflected upon to create themes. The final stage of the analysis involved the integration of the categories and themes into a framework for understanding the concepts from the perspective of the participants. Excerpts from interview transcripts were integrated to illustrate concepts and to support each theme. Aside from interview data, detailed field notes, memos and personal journal helped triangulate the findings. Team debriefings occurred at several stages during the analysis.

\section{Results}

\subsection{Cross-Sectional Study}

\subsubsection{Background Information}

Of the 639 participants, there were more females $(64.9 \%)$ than males $(35.1 \%)$. The mean age for both groups was 29 years (Table S1).

\subsubsection{Fear of HIV/AIDS in the Era of ART}

Most participants felt that the community's fear of HIV/AIDS was reduced with the availability of ART (89.4\%; CI: 86.3-92.0\%) (Figure 1). This proportion was similar for male $(86.8 \%$; CI: $80.4-91.3 \%)$ and female participants (90.8\%; CI: 86.9-93.6\%). No statistical difference was found between this outcome and any demographic or knowledge measures in the multivariable logistic regression model (Table S2). Most participants were fearful of contracting HIV/AIDS (94.1\%, CI: 91.1-96.2\%; males: 93.7\%; CI: 88.3-96.7\%; females: 94.4\%; CI: 90.3-96.8\%). Fewer participants reported that their personal fear of the disease had been reduced with the availability of ART $(22.4 \%$; CI: $18.2-$ $27.2 \%$; Figure 1), which included $24.4 \%$ of males (CI: $17.7-32.7 \%$ ) and $21.2 \%$ of females (CI: $16.1-27.4 \%$ ). Participants who had at least a secondary level education were less likely to report a reduced personal fear of HIV/AIDS (Odds ratio, $\mathrm{OR}=0.29, \mathrm{p}=0.022$ ), while those who were aware of the negative effects of ART were more likely to report a reduced personal fear of HIV/AIDS $(\mathrm{OR}=1.72, \mathrm{p}=0.047)$ with the availability 
Figure 1. Fear of HIV/AIDS among 18 to 49-year-old residents of Rwimi, Uganda.

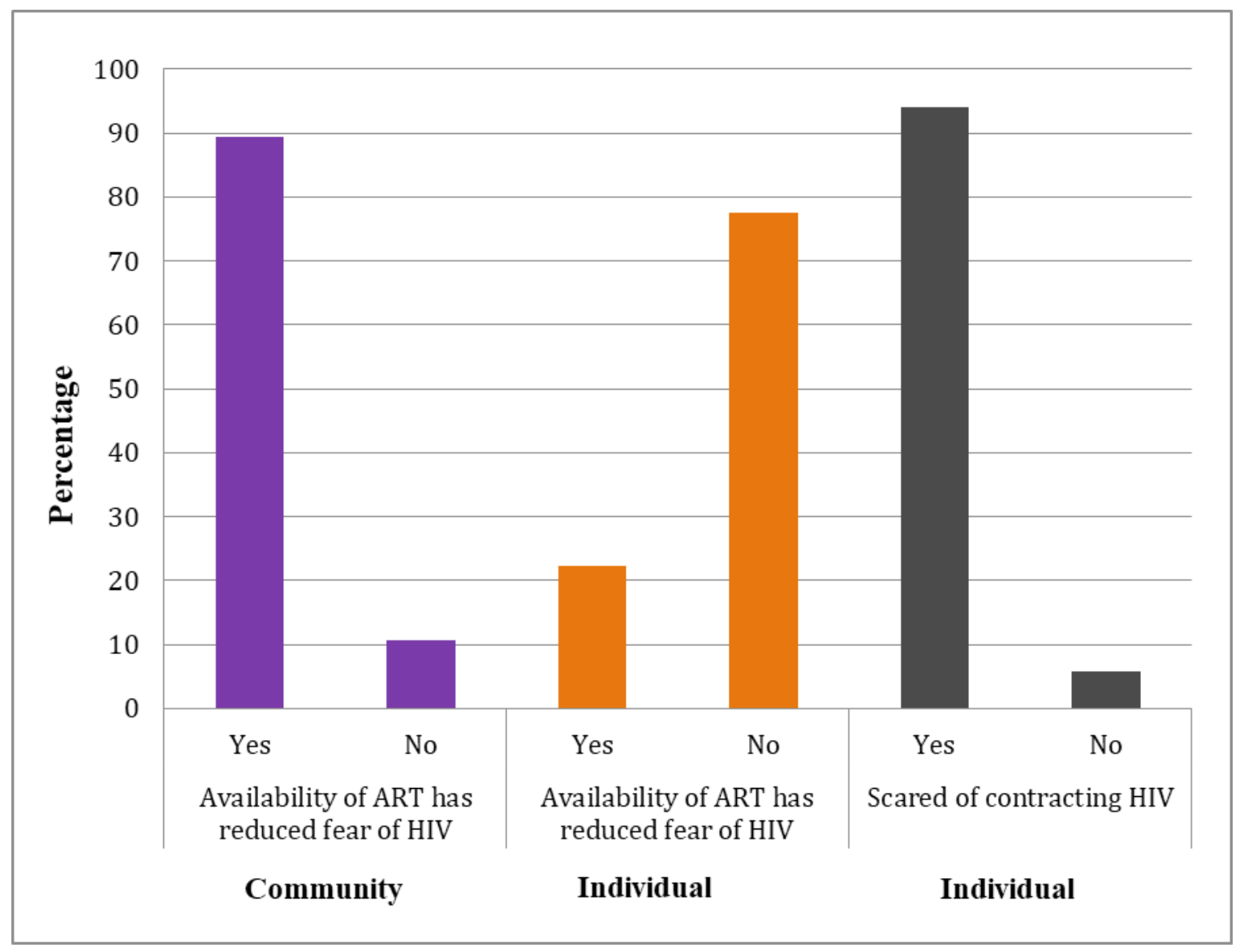

of ART (Table S3).

\subsubsection{HIV/AIDS-Related Attitudes and Prac-} tices

The majority of participants, $71.7 \%$ of males and $88.8 \%$ of females, had tested for HIV (Table S4). Most participants (87.3\%) said they would inform their partners if they were HIV positive and would like to be informed (97.7\%) if their partner was HIV positive. More females $(53.8 \%)$ than males $(42.8 \%)$ felt they were at risk of contracting HIV. "Distrustful of partner" $(69.8 \%)$ made participants feel at risk while "fidelity" $(60.2 \%)$ and "condom use" (39.8\%) made them feel safe. "Faithfulness to partner" $(71.3 \%)$ was the most common prevention practice among participants. Condoms had been used by only $25.3 \%$ of the sexually active participants during their last sexual encounter (for males and females, respectively: $31.7 \%$ and $22.1 \%$ ).

\subsection{Qualitative Description}

\subsubsection{Beliefs About ART}

Participants believed that ART was successful in treating HIV/AIDS but knew that it did not cure HIV/AIDS. They also shared their perceptions on the limitations of ART, including the need to adhere to treatment.

When you get infected with HIV/AIDS, you need to take good care of yourself so that the drugs are effective in your body. If you miss taking drugs at a specific time, you might fall sick and get problems. [Male]

\subsubsection{Fear of HIV/AIDS With the Availabil-} ity of ART

Some participants reported that the availability of ART had reduced their fear of HIV/AIDS.

Yes, I am less fearful because I know I can live for $30-40$ years with [ART]. [Male] 
I am less fearful because in the past before drugs, people would be recognized from HIV/AIDS signs. Those signs were so bad [...] but these days they are no longer there. [Female]

However, participants mentioned that ART has not completely removed the fear of HIV/AIDS because it is not a cure.

I still fear HIV/AIDS because it is an incurable disease; it cannot be treated for you to get healed. Even if you take ARTs, it is no cure. Drugs just treat it. [Male]

Some participants felt that the ability of ART to make HIV/AIDS positive persons look healthy was contributing to the spread of the disease, which led to an increased fear of being infected.

It is difficult to recognize someone on drugs. The person looks good and healthy, you end up having sex with them, and then later on you hear that you are HIV/AIDS positive. [Female]

The stigma of being HIV/AIDS positive persisted in people's minds and contributed to the fear of HIV/ AIDS.

Everywhere you go, you would have to carry ARTs, yet you fear a person seeing you taking them; that is why I fear HIV/AIDS. [Male]

\subsubsection{Attitudes Towards HIV/AIDS Preven- tion Practices}

Participants discussed their current prevention practices which revolved around common themes in the Ugandan context of abstinence, being faithful, using condoms and testing for HIV/AIDS (Table S4).

I avoid having extra marital affairs. You stick to your husband and find time to test with your spouse. [Female]

I do have a girlfriend at the moment but I have told her to go for HIVIAIDS testing first before we do anything. [Until then], we are still abstaining from sex. [Male]
I also use condoms for fear of getting HIV/AIDS. [Male]

There were differences in perceptions of socially accepted sexual behaviours between men and women. Most women perceived being unfaithful in their marriage as a taboo and were not open to discussing it. Instead, women tended to focus more on their own acts of abstinence and fidelity.

I was abstaining from sex in the past as a way of protecting myself against HIV/AIDS before I got engaged. After getting married I decided to be faithful to my husband. [Female]

Some men, on the other hand, appeared indifferent towards issues of infidelity in their relationships.

Us businessmen, we cannot keep travelling with our wives. You may move from here to Kampala and spend a whole month there. You cannot spend a full month without having sex. It's not possible because men are sexually active. [Male]

Condom use among married couples was not popular and it was seen as a sign of trust in the relationship not to use condoms. Thus, condoms were mainly used in relationships with people who were not their regular partners.

With your official wife, you may not use condoms, but when you go outside you must protect yourself. [Male]

Married women whose spouses travelled frequently and whose fidelity they were unsure of also requested condom use.

I am protecting myself as a woman when my man is away. When he returns we first use condoms then go for check-up the following day. He already knows that. [Female]

Both sexes agreed that women tested more often than men. This was attributed to the routine counselling and testing women undergo during antenatal services. ART availability was not a key motivator for testing. Several participants mentioned that they got tested just 
to know their status. Additionally, experiences with long illnesses or a partner who had contracted HIV/ AIDS pushed people to get tested.

What forced me to test? I saw that I was falling sick so often. I said maybe I have HIV/AIDS, let me go and test and if I am positive, I treat it early before it kills me. [Female]

Among the male participants, distrust of their partner, insecurities about their own sexual behaviours and experiences with a partner diagnosed with HIV/ AIDS were enablers for testing. Some men were waiting to see signs that they might be sick (e.g. feverishness) before getting tested for HIV/AIDS. Others also used the HIV/AIDS status of their partners as a measure for their own HIV/AIDS status.

I have never been tested for HIV/AIDS. When my wife was expecting they tested her for HIV/AIDS. She was negative. She tested again and was negative. By seeing her results, I knew that my HIVI AIDS status was negative too. [Male]

Figure 2: Framework for context of fear of HIV/AIDS in the era of HAART in Rwimi, Uganda.

\begin{tabular}{|c|c|c|c|c|c|c|}
\hline \multicolumn{7}{|c|}{ Factors influencing the fear of HIV/AIDS } \\
\hline \multicolumn{2}{|c|}{ Mitigating effects of ART } & \multicolumn{2}{|c|}{ Fear of being infected } & Stigma & \multicolumn{2}{|c|}{ Inconvenience of being on ART } \\
\hline \multicolumn{7}{|c|}{ Factors influencing the fear of HIV/AIDS } \\
\hline \multicolumn{7}{|c|}{ Response to the fear of HIV/AIDS } \\
\hline Abstinence & \multicolumn{2}{|c|}{ Be faithful } & Condom use & \multicolumn{2}{|c|}{ Testing for HIV } & $\begin{array}{l}\text { Separation from HIV } \\
\text { positive partner }\end{array}$ \\
\hline \multicolumn{7}{|c|}{ Socio-cultural influences on HIV prevention practices } \\
\hline \multicolumn{3}{|c|}{ Trust in the relationship } & \multicolumn{2}{|c|}{ Gender roles } & & Policy \\
\hline
\end{tabular}


We also found that the stigma associated with being HIV positive made the fear persist. This was consistent with the 2013 Ugandan stigma index, which reported experiences of both external and internal stigma (Uganda AIDS Commission 2014). Forms of external stigma identified included gossip, verbal harassment and sexual rejection, while the forms of internal stigma included self-blame, low self-esteem, shame, guilt and blaming others. Fear of HIV/AIDS has been associated with these forms of stigma mentioned (Ha et al. 2012; Herek et al. 2002). The sources of stigma include fear of illness, fear of contagion and fear of death. These tend to be common reactions among health workers, coworkers, caregivers and the general population (Brown et al. 2003; Walusimbi and Okonsky 2004).

Our assessments on HIV prevention practices showed that the fear of HIV/AIDS directed the use of the following preventative practices: abstinence, being faithful to one partner, condom use, testing for HIV and separating from an HIV positive partner (Table S4). However, how these practices were conducted was influenced by certain socio-cultural norms - gender expectations, expectations of trust in relationships and policy (Figure 2). Among women, for instance, the routine testing and counseling policy at antenatal services made it the norm for pregnant women to test for HIV to prevent mother-to-child HIV transmission. Most of our female participants expressed that they had been tested because they were pregnant. This policy is part of the norms that influence HIV testing in the community. We also found that trust in relationships influenced condom use as a preventative practice. There was an expectation of trust in long-term relationships. Therefore, these couples were not expected to use condoms. This could lead to the under-use of condoms for HIV prevention and an increased potential for the spread of HIV in cases of undisclosed infidelity. Prevention practices were also complicated by the fear of social stigma associated with disclosing one's HIV positive status and the fear of destabilizing the family unit. Larsson et al. found a similar sentiment of unwillingness to disrupt the family harmony even in an atmosphere of distrust between the couple (2010).

Societal expectations regarding gender roles (the man as the primary wage earner and the woman as the home-maker) backed by the power structure of relationships (the male as the head of the household) also influenced prevention practices. Therefore, women in relationships in which there was infidelity tended to feel compelled to stay with men who were unfaithful because of the security offered by the marriage - financial, social, emotional, physical, etc. - as well as because of their children. As shown in our qualitative study, while some men perceived unfaithfulness in relationships as part of a natural male inclination, women often perceived abstinence and faithfulness as a societal expectation of themselves. This finding is reflected in the results of the 2011 Ugandan AIDS Indicator Survey which showed that the proportion of men who had two or more sexual partners in the past 12 months was more than six times higher than the proportion of women: 19\% versus 3\% (Uganda Ministry of Health and ICF International 2012).

Using a combination of quantitative and qualitative measures was a strength in our study. This study yields a deeper understanding of the factors that influence behaviours around prevention, which should be considered when designing HIV prevention programs. Our results also support previous research on how socio-cultural norms can influence health promotion (Courtenay 2000; Green and others 2013). Limitations may include the subjectivity involved in the definition of fear, the possibility of social desirability bias in some participants' responses and a potential gender bias. Since we had more females than males participate in our survey, we attempted to correct for the latter by weighting the data to reflect the Rwimi population. The socio-cultural factors such as gender roles and relationship dynamics (power structures and trust) that influence HIV/AIDS prevention practices are noteworthy and deserve further evaluation. However, our data was not sufficient to draw detailed conclusions on this topic. We encourage considering socio-cultural influences in designing HIV-related public health programs in communities such as Rwimi. For instance, incorporating entrepreneurial training and microcredit into HIV/AIDS education programs could empower women to make informed decisions about their health and well-being. We also encourage similar studies to be conducted in other Sub-Saharan countries, as such information is imperative to planning sustainable programs to promote adherence to HIV/AIDS prevention practices.

\section{Conclusions}

Personal fear of HIV/AIDS persists in Rwimi, 
but with the availability of life-prolonging ART, this fear has been reduced. HIV/AIDS prevention practices are influenced by socio-cultural norms such as gender roles, relationship dynamics and trust, which should all be considered in designing sustainable HIV prevention programs. This change in programming could help to reduce the incidences of HIV cases and improve the quality of life of people already living with HIV/AIDS.

\section{Disclosure Statement}

The authors declare that they have no relevant or material financial interests that relate to the research described in this paper.

\section{Acknowledgements \\ This study was funded by the Canadian Institutes of Health Research (CIHR) grant number FRN 111204. We thank the participants as well as the Ugandan research team -Banura Lilian, Clif Richard, Birungi Janephar, Kakyo Flavia and Kwesiga Enoch - for their support in collecting the data.}

\section{Cite As}

Ofosu N.N., Saunders L.D. Jhangri G. and Alibhai A. 2018. The impact of the availability of antiretroviral therapy on personal and community fear of HIV?AIDS, and HIV prevention practices in Rwimi, Uganda: A mixed-method study. Alberta Academic Review Journal, Vol (1): 1-14, DOI: 10.29173/ aar11 .

\section{References}

Aplin LCR. 2012. The Influence of a Community-based HIV/ AIDS treatment project on HIV/AIDS knowledge, attitudes, and prevention practices in rural Uganda. In: Alberta Uo, editor.: ProQuest, UMI Dissertations Publishing, 2012, MR90168.

Apondi R, Bunnell R, Ekwaru JP, Moore D, Bechange S, Khana K, King R, Campbell J, Tappero J, Mermin J. 2011. Sexual behavior and HIV transmission risk of Ugandan adults taking antiretroviral therapy: 3 year follow-up. Aids 25(10):13171327.

Atuyambe L, Neema S, Otolok-Tanga E, Wamuyu-Maina G, Kasasa S, Wabwire-Mangen F. 2008. The effects of enhanced access to antiretroviral therapy: a qualitative study of community perceptions in Kampala city, Uganda. African Health Sciences 8(1):13-19.

Brown L, Macintyre K, Trujillo L. 2003. Interventions to reduce HIV/AIDs stigma: What have we learned? Aids Education and Prevention 15(1):49-69.

Courtenay WH. 2000. Constructions of masculinity and their influence on men's well-being: a theory of gender and health. Social Science \& Medicine 50(10):1385-1401.

Demmer C. 2003. HIV prevention in the era of new treatments. Health Promot Pract 4(4):449-56.
Diabate S, Alary M, Koffi CK. 2008. Short-term increase in unsafe sexual behaviour after initiation of HAART in Cote d'Ivoire. AIDS 22(1):154-6.

Green EC, Kajubi P, Ruark A, Kamya S, D’Errico N, Hearst N. 2013. The Need to Reemphasize Behavior Change for HIV Prevention in Uganda: A Qualitative Study. Studies in Family Planning 44(1):25-43.

Ha TH, Liu HJ, Li J, Nield J, Lu ZP. 2012. Psychometric assessment of scales measuring HIV public stigma, drug-use public stigma and fear of HIV infection among young adolescents and their parents. Aids Care-Psychological and Socio-Medical Aspects of Aids/Hiv 24(1):39-45.

Herek GM, Capitanio JP, Widaman KF. 2002. HIV-related stigma and knowledge in the United States: Prevalence and trends, 1991-1999. American Journal of Public Health 92(3):371377.

Kaye DK, Kakaire O, Osinde MO, Lule JC, Kakande N. 2013. The impact of highly active antiretroviral therapy on highrisk behaviour of HIV-infected patients in sub-Saharan Africa. J Infect Dev Ctries 7(6):436-47.

Luchters S, Sarna A, Geibel S, Chersich MF, Munyao P, Kaai S, Mandaliya KN, Shikely KS, Rutenberg N, Temmerman M. 2008. Safer sexual behaviors after 12 months of antiretroviral treatment in Mombasa, Kenya: a prospective cohort. AIDS Patient Care STDS 22(7):587-94.

Mayan MJ. 2009. Essentials of qualitative inquiry. Walnut Creek, California: Left Coast Press

Moatti JP, Prudhomme J, Traore DC, Juillet-Amari A, Akribi HA, Msellati P, Cote d'Ivoire HIVDAIS-BEG. 2003. Access to antiretroviral treatment and sexual behaviours of HIV-infected patients aware of their serostatus in Cote d'Ivoire. AIDS 17 Suppl 3:S69-77.

Morse JM, Niehaus L. 2009. Mixed method design: principles and procedures. Walnut Creek, California: Left Coast Press.

Muthusamy N, Levine TR, Weber R. 2009. Scaring the Already Scared: Some Problems With HIV/AIDS Fear Appeals in Namibia. Journal of Communication 59(2):317-344.

Nachega JB, Lehman DA, Hlatshwayo D, Mothopeng R, Chaisson RE, Karstaedt AS. 2005. HIV/AIDS and antiretroviral treatment knowledge, attitudes, beliefs, and practices in HIVinfected adults in Soweto, South Africa. J Acquir Immune Defic Syndr 38(2):196-201.

Ostrow DE, Fox KJ, Chmiel JS, Silvestre A, Visscher BR, Vanable PA, Jacobson LP, Strathdee SA. 2002. Attitudes towards highly active antiretroviral therapy are associated with sexual risk taking among HIV-infected and uninfected homosexual men. AIDS 16(5):775-80.

Pearson CR, Cassels S, Kurth AE, Montoya P, Micek MA, Gloyd SS. 2011. Change in sexual activity 12 months after ART initiation among HIV-positive Mozambicans. AIDS Behav 15(4):778-87.

Sandelowski M. 2000. Whatever happened to qualitative description? Research in Nursing \& Health 23(4):334-340.

Smith RM, Carrico AW, Montandon M, Kwena Z, Bailey R, Bukusi EA, Cohen CR. 2011. Attitudes and beliefs about anti-retroviral therapy are associated with high risk sexual behaviours among the general population Kisumu, Kenya. 
Aids Care-Psychological and Socio-Medical Aspects of Aids/ Hiv 23(12):1668-1675.

StataCorp. 2011. College Station, TX: StataCorp LP, 2011. p. Stata Statistical Software: Release 12.

Stolte IG, Dukers NH, Geskus RB, Coutinho RA, de Wit JB. 2004. Homosexual men change to risky sex when perceiving less threat of HIV/AIDS since availability of highly active antiretroviral therapy: a longitudinal study. AIDS 18(2):3039.

The Antiretroviral Therapy Cohort Collaboration. 2005. The changing incidence of AIDS events in patients receiveing highly active antiretroviral therapy. Arch Intern Med 165(4):416-423.

Uganda AIDS Commission. 2014. HIV and AIDS: Uganda Country Progress Report - 2014.

Uganda Ministy of Health and ICF International. 2012. 2011 Uganda AIDS Indicator Survey: Key Findings. Calverton, Maryland, USA: MOH and ICF International.

UNAIDS. 2013. Global report: UNAIDS report on the global AIDS epidemic 2013. UNAIDS.

Walusimbi M, Okonsky JG. 2004. Knowledge and attitude of nurses caring for patients with HIV/AIDS in Uganda. Applied Nursing Research 17(2):92-99.

World Health Organisation. Global Update on HIV Treatment 2013: Results, Impact and Opportunities [Internet]. October, 2014]. Available from: http://www.unaids.org/sites/default/ files/en/media/unaids/contentassets/documents/unaidspublication/2013/20130630_treatment_report_en.pdf

World Health Organisation. HIV/AIDS: Treatement and care [Internet]. Available from: http://www.who.int/hiv/topics/treatment/en/ 


\section{Supplementary Materials}

Supplementary materials contain the interview questionnaires organized in: Table S1 to Table S4.

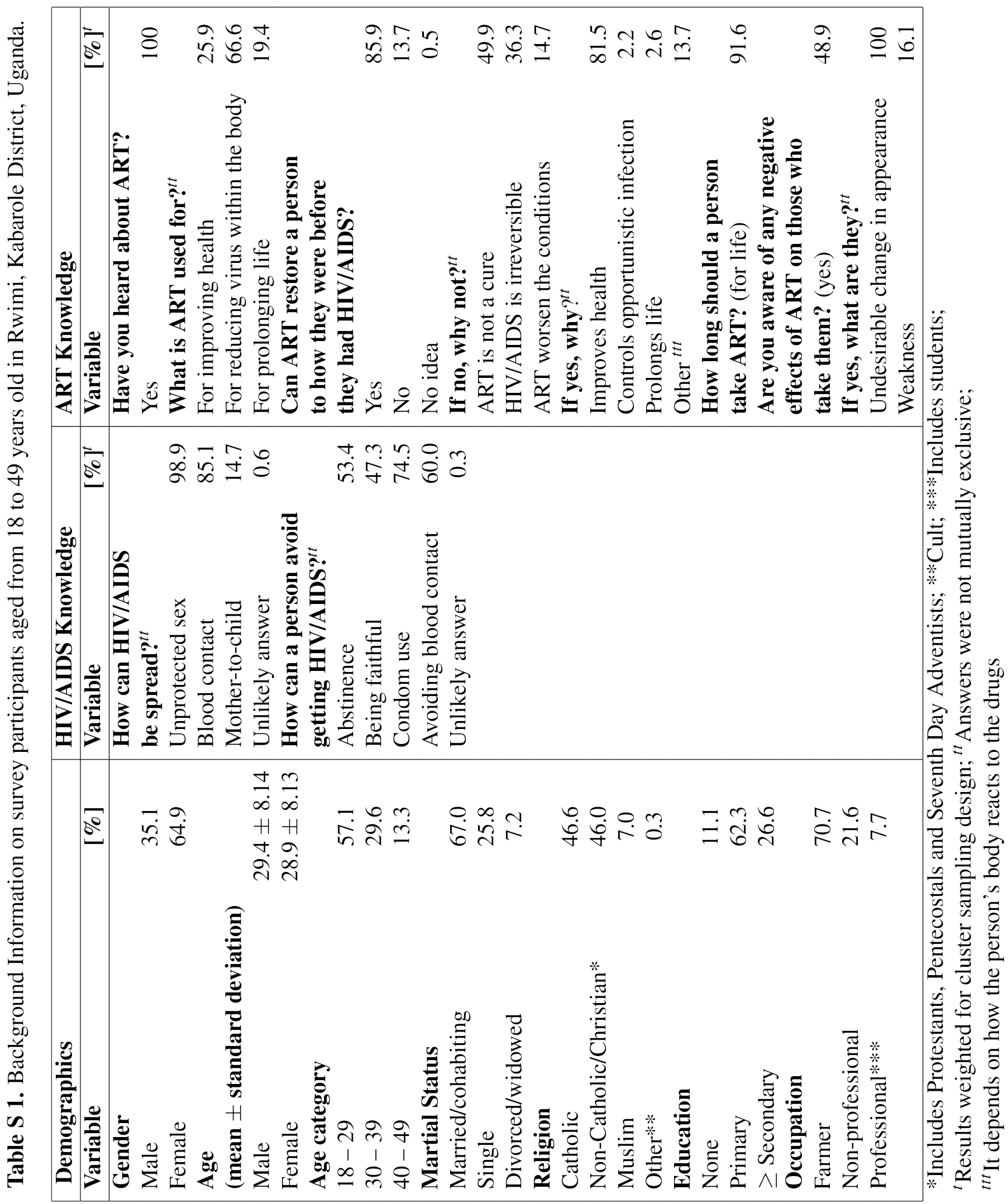


Table S 2. Odds ratios (OR) and $95 \%$ confidence intervals (CI) of reduced fear of HIV/AIDS (in the community) among survey participants aged from 18 to 49 years old in Rwimi, Kabarole District, Uganda.

\begin{tabular}{|c|c|c|c|c|}
\hline & \multicolumn{2}{|c|}{ Univariate Analysis* } & \multicolumn{2}{|c|}{ Multivariable Analysis* } \\
\hline Variable & OR $(95 \%$ CI $)$ & p-value & OR $(95 \%$ CI $)$ & p-value \\
\hline \multicolumn{5}{|l|}{ Gender } \\
\hline Male & 1.00 & & & \\
\hline Female & $1.51(0.82-2.77)$ & 0.184 & $1.69(0.91-3.14)$ & 0.098 \\
\hline \multicolumn{5}{|l|}{ Age Category } \\
\hline $18-29$ & 1.00 & & & \\
\hline $30-39$ & $0.95(0.50-1.82)$ & 0.882 & $1.03(0.51-2.09)$ & 0.934 \\
\hline $40-49$ & $1.44(0.57-3.67)$ & 0.444 & $1.65(0.62-4.38)$ & 0.318 \\
\hline \multicolumn{5}{|l|}{ Martial Status } \\
\hline Married/cohabiting & 1.00 & & & \\
\hline Single & $0.73(0.36-1.46)$ & 0.370 & & \\
\hline Divorced/widowed & $1.39(0.38-5.14)$ & 0.622 & & \\
\hline \multicolumn{5}{|l|}{ Religion } \\
\hline Catholic & 1.00 & & & \\
\hline Non-Catholic/Christian & $1.55(0.82-2.93)$ & 0.181 & & \\
\hline Muslim & $1.12(0.41-3.06)$ & 0.831 & & \\
\hline \multicolumn{5}{|l|}{ Education } \\
\hline None & 1.00 & & & \\
\hline Primary & $1.63(0.63-4.19)$ & 0.309 & $1.96(0.75-5.12)$ & 0.171 \\
\hline$\geq$ Secondary & $1.56(0.58-4.21)$ & 0.379 & $2.00(0.67-6.01)$ & 0.216 \\
\hline \multicolumn{5}{|l|}{ Occupation } \\
\hline Farmer & 1.00 & & & \\
\hline Non-professional & $1.04(0.53-2.06)$ & 0.910 & & \\
\hline Professional & $0.65(0.25-1.69)$ & 0.379 & & \\
\hline \multicolumn{5}{|c|}{ Can ART restore a person to how they were before they had HIV/AIDS? } \\
\hline No & 1.00 & & & \\
\hline Yes & $0.56(0.23-1.38)$ & 0.211 & & \\
\hline \multicolumn{5}{|c|}{ Are you aware of any negative effects of ART on those who take it? } \\
\hline No & 1.00 & & & \\
\hline Yes & $0.98(0.54-1.78)$ & 0.942 & & \\
\hline
\end{tabular}


Table S 3. Odds ratios (OR) and 95\% confidence intervals (CI) of reduced personal fear of HIV/AIDS among survey participants aged from 18 to 49 years old in Rwimi, Kabarole District, Uganda.*

\begin{tabular}{|c|c|c|c|c|}
\hline & \multicolumn{2}{|c|}{ Univariate Analysis** } & \multicolumn{2}{|c|}{ Multivariable Analysis** } \\
\hline Variable & OR $(95 \%$ CI $)$ & p-value & OR (95\% CI) & p-value \\
\hline \multicolumn{5}{|l|}{ Gender } \\
\hline Male & 1.00 & & & \\
\hline Female & $0.83(0.49-1.41)$ & 0.491 & $0.68(0.39-1.21)$ & 0.189 \\
\hline \multicolumn{5}{|l|}{ Age Category } \\
\hline $18-29$ & 1.00 & & & \\
\hline $30-39$ & $0.68(0.36-1.30)$ & 0.245 & $0.67(0.34-1.31)$ & 0.240 \\
\hline $40-49$ & $1.20(0.59-2.43)$ & 0.620 & $0.89(0.41-1.94)$ & 0.777 \\
\hline \multicolumn{5}{|l|}{ Martial Status } \\
\hline Married/cohabiting & 1.00 & & & \\
\hline Single & $0.93(0.52-1.68)$ & 0.818 & & \\
\hline Divorced/widowed & $1.04(0.39-2.76)$ & 0.941 & & \\
\hline \multicolumn{5}{|l|}{ Religion } \\
\hline Catholic & 1.00 & & & \\
\hline Non-Catholic/Christian & $0.97(0.56-1.67)$ & 0.907 & & \\
\hline Muslim & $1.01(0.31-3.28)$ & 0.981 & & \\
\hline \multicolumn{5}{|l|}{ Education } \\
\hline None & 1.00 & & & \\
\hline Primary & $1.13(0.52-2.42)$ & 0.760 & $0.99(0.43-2.24)$ & 0.974 \\
\hline$\geq$ Secondary & $0.40(0.16-1.03)$ & 0.057 & $0.29(0.10-0.84)$ & 0.022 \\
\hline \multicolumn{5}{|l|}{ Occupation } \\
\hline Farmer & 1.00 & & & \\
\hline Non-professional & $0.51(0.25-1.02)$ & 0.059 & & \\
\hline Professional & $0.73(0.25-2.16)$ & 0.568 & & \\
\hline \multicolumn{5}{|c|}{ Can ART restore a person to how they were before they had HIV/AIDS? } \\
\hline No & 1.00 & & & \\
\hline Yes & $0.68(0.29-1.59)$ & 0.379 & & \\
\hline \multicolumn{5}{|c|}{ Are you aware of any negative effects of ART on those who take it? } \\
\hline No & 1.00 & & & \\
\hline Yes & $1.60(0.94-2.71)$ & 0.081 & $1.72(1.00-2.95)$ & 0.047 \\
\hline
\end{tabular}


Table S 4. Attitudes and HIV/AIDS-prevention practices among survey participants aged from 18 to 49 years old in Rwimi, Kabarole District, Uganda.

\begin{tabular}{|c|c|}
\hline Variable & {$[\%] *$} \\
\hline Tested for HIV/AIDS & 83.1 \\
\hline Males who had tested for HIV/AIDS & 71.1 \\
\hline Females who had tested for HIV/AIDS & 88.8 \\
\hline \multicolumn{2}{|l|}{ If yes, why? } \\
\hline To know my status & 100 \\
\hline \multicolumn{2}{|l|}{ If no, why? } \\
\hline Confident of being HIV/AIDS negative & 55.2 \\
\hline Fear of results & 26.6 \\
\hline No reason & 48.7 \\
\hline Do you know your HIV status? (yes) & 77.8 \\
\hline Males who know their HIV status & 65.1 \\
\hline Females who know their HIV status & 84.0 \\
\hline \multicolumn{2}{|l|}{ Would you want to be informed of } \\
\hline your partner's HIV status? (yes) & 97.7 \\
\hline Males who would want to be informed & 98.2 \\
\hline Females who would want to be informed & 97.5 \\
\hline \multicolumn{2}{|l|}{ If yes, why?** } \\
\hline To protect self & 84.4 \\
\hline To plan for the future & 13.6 \\
\hline To support partner to start treatment & 32.8 \\
\hline To build trust & 2.0 \\
\hline \multicolumn{2}{|l|}{ If no, why not? } \\
\hline To prevent conflict & 100 \\
\hline Would your sexual practices change if you found out your & 95.0 \\
\hline Males whose sexual practices would change & 96.9 \\
\hline Females whose sexual practices would change & 94.1 \\
\hline \multicolumn{2}{|l|}{ If yes, how? $* *$} \\
\hline Condom use & 71.5 \\
\hline Abstinence & 9.1 \\
\hline Separation & 30.6 \\
\hline Reduced sex & 2.2 \\
\hline Would you inform your partner if you were HIV/AIDS positive? & 87.3 \\
\hline Males who would inform partner & 85.1 \\
\hline Females who would inform their partner & 88.4 \\
\hline \multicolumn{2}{|l|}{ If yes, why?** } \\
\hline To know each other's status & 85.9 \\
\hline To prevent conflict & 14.1 \\
\hline \multicolumn{2}{|l|}{ If no, why not? } \\
\hline Fear of partner's response to the situation & 100 \\
\hline
\end{tabular}




\begin{tabular}{|lc|}
\hline Continuation of Table S4. & \\
\hline Do you think you are at risk of getting HIV/AIDS? (yes) & 50.2 \\
Males who think they are at risk & 42.8 \\
Females who think they are at risk & 53.8 \\
If yes, what makes you think so?** & \\
Distrustful of partner & 69.8 \\
Lifestyle & 19.2 \\
Inconsistent use of condoms & 10.2 \\
Uncertainty of life & 9.6 \\
If no, what makes you think so?** & \\
Fidelity & 60.2 \\
Condom use & 39.8 \\
Have you been sexually active in the past 6 months? ${ }^{t}$ (yes) & 80.6 \\
What have you being doing to protect yourself & \\
from getting HIV/AIDS?** & \\
Abstinence & 3.4 \\
Faithfulness to partner & 71.3 \\
Condom use & 28.6 \\
Avoiding blood contact & 6.7 \\
Regular testing with partner & 2.8 \\
Nothing & 7.7 \\
Did you use a condom the last time you had intercourse? (yes) & 25.3 \\
Males & 31.7 \\
Females & 22.1 \\
If yes, why?** & \\
To prevent pregnancy & 38.8 \\
For protection & 84.4 \\
If no, why not?** & \\
No need for condoms & 36.5 \\
We trust each other & 31.5 \\
Partner refused to use condom & 27.5 \\
Condom unavailable at the time & 4.6 \\
Did you ever want to use a condom & \\
but did not use one? (yes) & 95.8 \\
Males & 96.2 \\
Females & 95.4 \\
If yes, why?** & 27.0 \\
Condom unavailable at the time & 59.5 \\
Partner refused to use condom & 16.2 \\
\hline Other*** & \\
\hline Resuls weigted for ctyst & \\
\hline
\end{tabular}

*Results weighted for cluster sampling design; **Answer are not mutually exclusive; ***Did not know how to use condoms, allergy/pain from using condoms, fear of condom breaking; ${ }^{t}$ Only participants who answered 'yes' to this question went on to answer the subsequent questions 